infection and indeed cerebral thrombophlebitis. However, he did not think that the fact that they were actually through the bone should deter them from using them.

HaRDy, A. G. (England) said they had experienced two unhappy episodesoddly enough one with a Blackburn and the other with a Cones' caliper. The one with a Blackburn produced regrettably a parietal abscess, which in spite of aspiration was eventually excised by the neurosurgeons and they had a paraplegia turned into a triplegia. The other one with the Cones' caliper slipped and went in, and they had an extradural infection. However, these were two cases out of 135 or so over many years, and he thought that if one went on long enough inevitably one would catch something.

GutTMANN, L. (England) said he was worried about the prone position in high cervical lesions, especially in cases who developed an ileus or were in respiratory distress. He personally would not dare to put high cervical lesions in prone position, and in his opinion one should add this as a contra-indication to that already mentioned by Mr. Harris and Mr. Wu.

Wu, P. (Scotland) said they looked after the Blackburn caliper every day pretty carefully; they cleaned up the skull wounds every day and sprayed with Polybactrin locally to make sure that no infection settled.

\title{
MYOTOMY OF ILIOPSOAS AND OBLIQUUS EXTERNUS ABDOMINIS FOR SEVERE SPASTIC FLEXION CONTRACTURE AT THE HIP
}

\author{
By L. S. Michaelis, M.D. (Berlin), L.R.C.P. \& S. (Ed.) \\ National Spinal Injuries Centre, Stoke Mandeville Hospital, England
}

\section{INTRODUCTION}

THE treatment of severe spastic flexion contracture at the hip in paraplegic and tetraplegic patients poses a number of problems. Passive extension-exercises alone are generally unable to improve the condition in these cases and may even increase the lordosis of the lumbar spine already caused by the contracture of the iliopsoas.

In complete lesions, particularly in women and older men, the alcohol block is the method of choice, but in younger men one will hesitate to sacrifice potency and a well-established automatic bladder. Most difficult to achieve is correction of the contracture and reduction of spasticity in incomplete lesions.

This is a report on the results of proximal myotomy of the iliopsoas on 14 severely spastic patients with extreme flexion-contracture at the hip carried out over the last four years. In Io patients the operation was done bilaterally so that the results of 24 operations can be reviewed. The age of the patients ranged from I3 to 57 years. In seven paraplegia or tetraplegia was due to trauma, in the other seven to either tumor or disease of the cord or spine. The neurological levels were cervical in four, upper thoracic in four and lower thoracic in six cases. In all patients but two the lesions were incomplete. In the majority of cases iliopsoas 
myotomy was combined with obturator neurectomy and done from the same incision. The Table pp. 290-9I shows further details.

\section{TECHNIQUE OF ILIOPSOAS MYOTOMY (fig. I)}

From an oblique lower abdominal incision the iliac fascia is split longitudinally, the femoral nerve freed and held aside with soft tape. The belly of iliopsoas is divided with the diathermy knife at a level about 3-4 in. proximal to the obturator
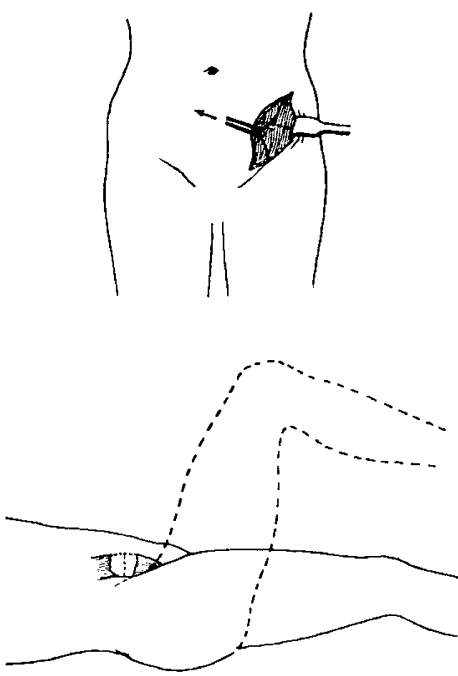

FIG. I

Iliopsoas Myotomy. Skin retracted laterally, femoral nerve retracted medially. Site of transverse division of $\mathrm{mm}$. psoas and iliacus.

(From: Michaelis, L. S. Orthopaedic Surgery of the Limbs in Paraplegia.)

membrane. After complete division a narrow strip of the ilium is visible. When the still strongly flexed thigh is now extended, the surgeon can observe the distal part of the muscle to slide $\mathrm{I}-2$ in. distally on the ilium, until contracture is completely corrected. Obturator neurectomy is performed before myotomy from the same skin incision.

\section{POST-OPERATIVE TREATMENT}

Abduction exercises are started on the first post-operative day. The patient stays in bed for a fortnight and spends one further week in the wheelchair. At the end of three weeks he starts standing exercises and begins to walk. In most cases passive extension exercises are unnecessary.

\section{RESULTS}

Contracture was and has remained completely corrected in II cases. In the patient with D.S. rapid progress of the disease made an alcohol block necessary two years later. In the two elderly men osteoarthritis of the hips and ectopic ossification limited correction by $20^{\circ}$.

Eleven patients were enabled to stand. Seven patients could after the operation walk with elbow crutches.

The following patient is described as an example: 
A hairdresser, aged 2I, a strongly built man, injured his lower back in a car accident. There was severe pain in the back. Radiograms showed no bony injury, but lumbar puncture showed a complete block. After myelography next day a tumor was removed from the spinal canal at the level of T8 which proved to be a neurofibroma.

He was admitted to the Centre six weeks later with pressure sores over the sacrum and heels. He was then slightly spastic with an incomplete lesion below Tro and early contractures of both hips. Spasticity rapidly increased with severe adduction and flexion

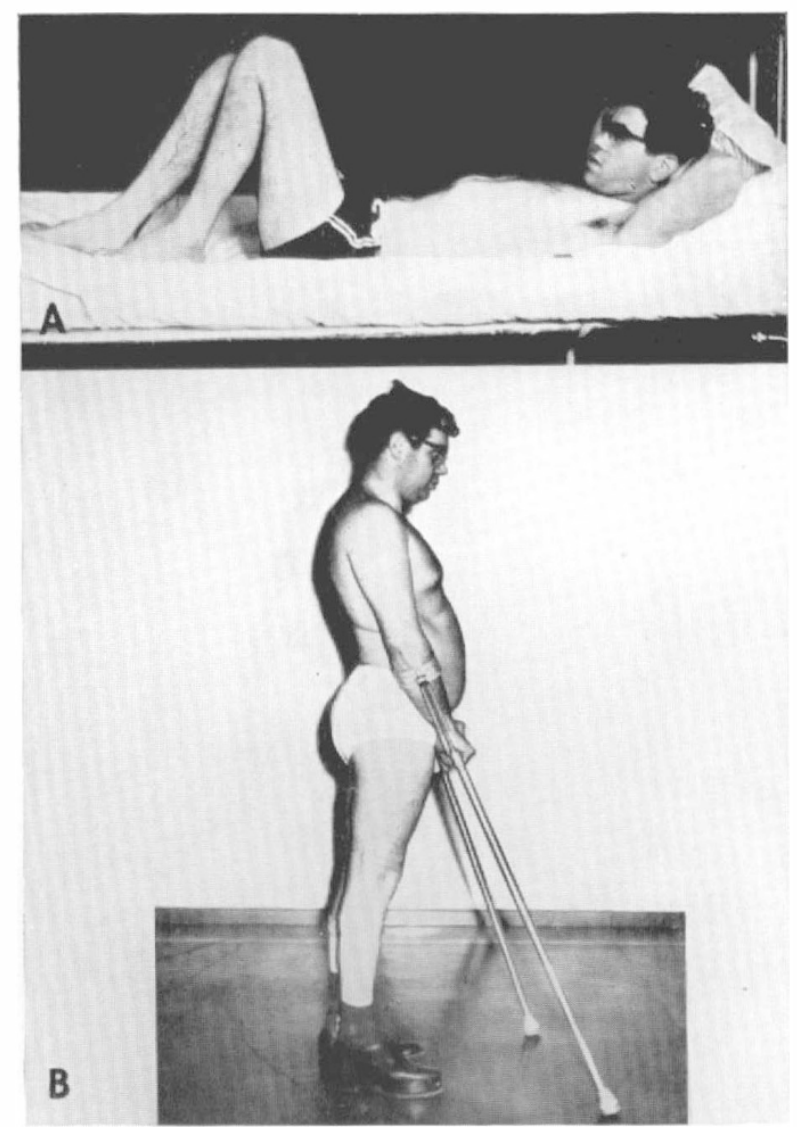

FIG. 2

Before and $3 \frac{1}{2}$ years after operations. (Case 6 on Table.)

contractures of both hips. Obturator-neurectomy and iliopsoas myotomy were carried out first on the left side, and two months later on the right side. Three months later he was discharged, being able to walk with elbow crutches.

He was readmitted 17 months later when residual spasticity and bilateral pes equinus were treated with bilateral lengthening of the tendo Achillis. Since then he stands and walks 'all day' with elbow crutches at work (fig. 2).

The only complications were in one case superficial bleeding due to insufficient haemostasis in the lax subcutaneous tissue of an elderly woman, and a deep haematoma occurring II days after operation in the patient shown in Figure 2 who 


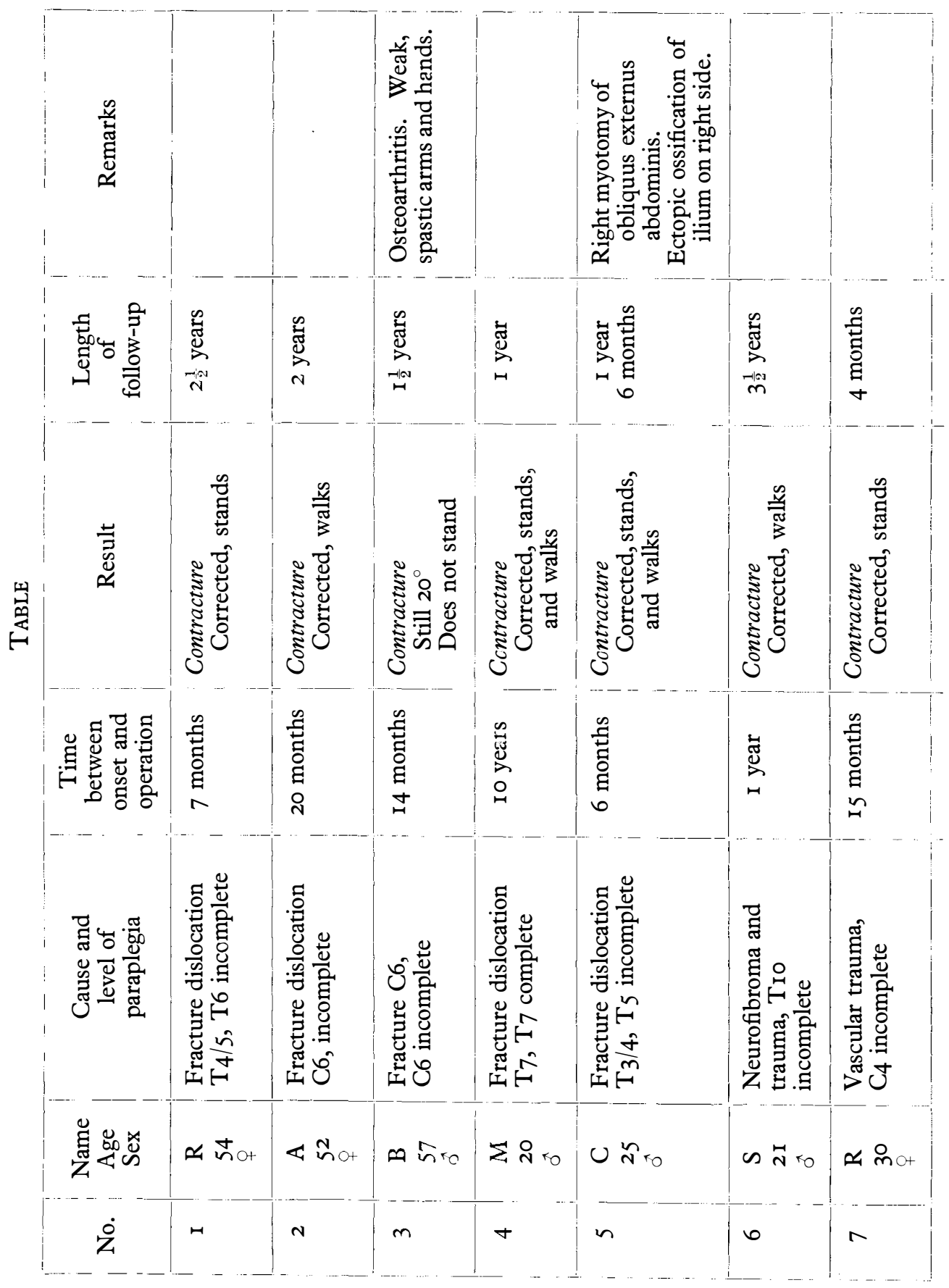




\begin{tabular}{|c|c|c|c|c|c|c|}
\hline 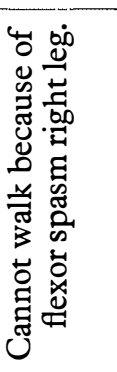 & & 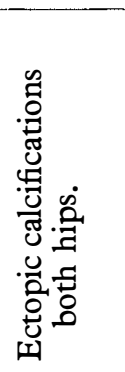 & & & & 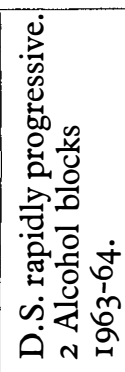 \\
\hline  & 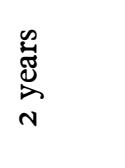 & 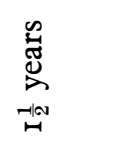 & 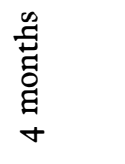 & 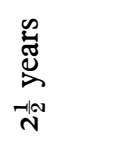 & 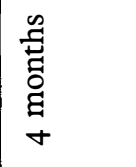 & 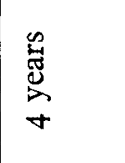 \\
\hline 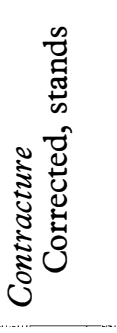 & 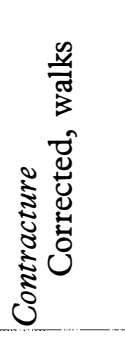 & 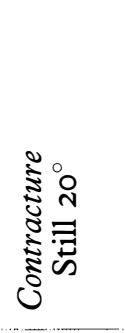 & 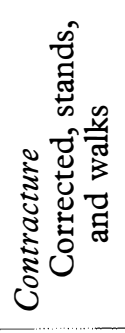 & 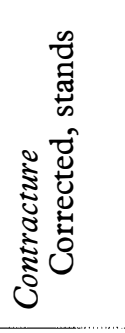 & 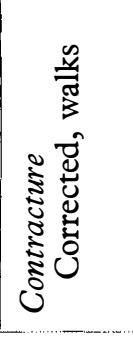 & 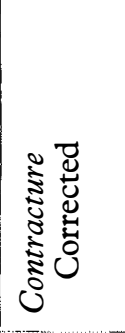 \\
\hline $\begin{array}{l}\stackrel{\vec{\nexists}}{2} \\
\stackrel{\sim}{\sim}\end{array}$ & 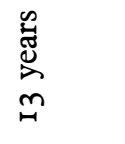 & 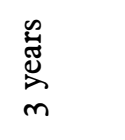 & 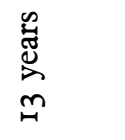 & 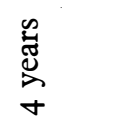 & 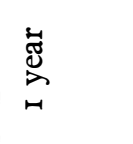 & 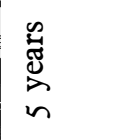 \\
\hline 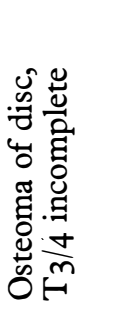 & 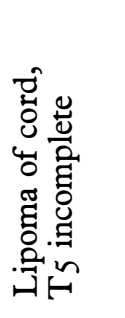 & 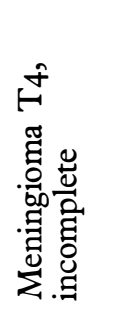 &  & 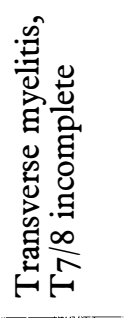 & 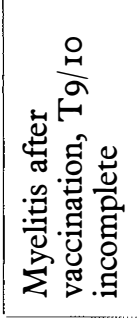 & 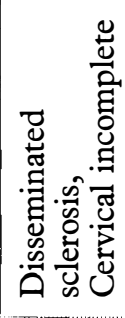 \\
\hline$\curvearrowleft \stackrel{N}{m} \circ+$ & $\cup \stackrel{n}{n}$ ot & a inro & $a \tilde{v} r_{0}$ & $B m_{\text {Ot }}$ & $0 \approx$ ot & w $\stackrel{\infty}{m \times 0}$ \\
\hline$\infty$ & $a$ & $\stackrel{\circ}{\circ}$ & $\Xi$ & $\mathbb{N}$ & $\stackrel{m}{m}$ & t \\
\hline
\end{tabular}


had been permitted to start standing I I days after the operation. The haematoma was absorbed after three weeks and did not influence the result.

\section{SPASTIC CONTRACTURE OF OBLIQUUS EXTERNUS ABDOMINIS}

One patient, No. 5 in the table, deserves special mention. He was not only one of the most severe cases of spasticity we have ever seen but also the first in our experience who showed severe one-sided spasticity of the external oblique muscle causing scoliosis and a tilt of the pelvis resulting in pseudo-shortening of the right leg.

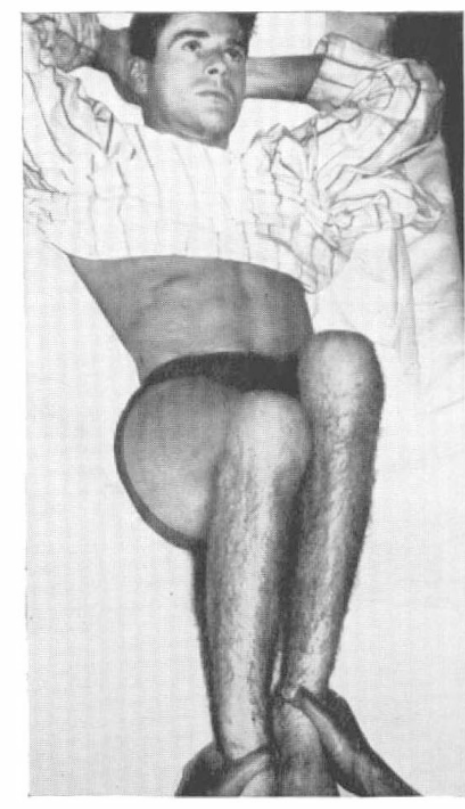

A

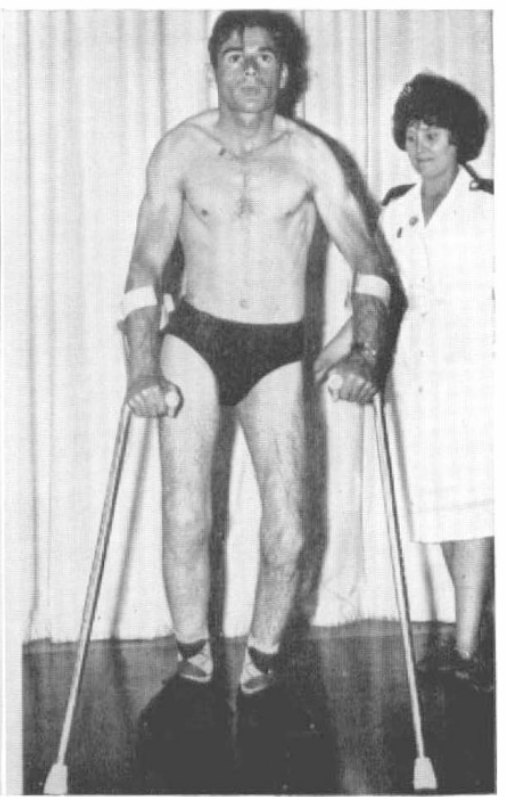

Fig. 3

B

Before and at the end of the series of operations including myotomy of obliquus externus abdominis on right side. (Case 5 on Table.)

He was admitted about a month after a road accident with a head injury, a fracture dislocation of $\mathrm{T}_{3} / 4$ vertebrae with paraplegia incomplete below $\mathrm{T}_{5}$ and fractures of the left clavicle and third rib. At first he was mentally disturbed and not easy to handle. Figure 3a shows the contractures at his hips before the start of operative correction. Step by step spasticity and contractures were treated by the following operations: bilateral obturator-neurectomies and iliopsoas myotomies, teno-myotomies of hamstrings and biceps and lengthening of the Achilles tendon. Eventually he was able to stand, but the pronounced pelvic tilt made it necessary to raise the right shoe by 2 in. In spite of this he was unable to walk, as sudden spasm of the right external oblique tended to throw him off balance. It was therefore decided to divide the bundles of external oblique transversely for about 3 in. at a level I in. proximal to the iliac crest. Since that operation spasticity has disappeared and he now walks safely. 
A further complication in this case was extensive ectopic ossification on the right side, particularly over the inner aspect of the ilium where the bony bulge was 2 in. thick and impinged on the course of the external iliac vessels.

Residual contracture and pseudo-shortening of the leg still demand a $I$ in. raise of the right shoe. The left knee had been used in slight flexion in order to make up for the shortening and for a time he walked with a straight P.O.P. backsplint on the left leg. This was discarded in due course.

\section{DISCUSSION}

Tenotomy of iliopsoas below or above the obturator-membrane, with or without detachment of the minor trochanter, has been practised for a long time. Results were not often satisfactory since contracture could only be partially corrected and spasticity was hardly influenced. Proximal myotomy has given better results by denervating the distal part of the muscle, permitting retraction of the proximal part and complete correction of the contracture.

Fowler (I957) divided the bellies of both iliopsoas and recti abdominis from a long transverse incision in three cases of advanced D.S. For such patients we would prefer the alcohol block.

High division of the iliopsoas is particularly suited for patients with incomplete lesions. Slight active or spastic flexion of the hip can still be obtained by rectus femoris and sartorius. Moreover, we differ from Fowler in the choice of incision. Neither long transverse nor median incisions should be used in order to avoid interfering with the function of the automatic bladder.

\section{SUMMARY}

Proximal myotomy of iliopsoas in cases of severe spastic flexion contracture at the hip has given reliable results, namely permanent correction of the contracture and reduction of spasticity, in 24 operations on 14 patients. In one patient onesided spasticity of external oblique complicated the clinical symptoms, and this was treated by transverse myotomy with a good result.

\section{RÉSUMÉ}

La myotomie proximale de l'iliopsoas dans les cas de spasticité sévère en flexion, avec contractures au niveau de la hanche, a donné de bons resultats qui sont: la correction permanente des contractures, et, la réduction de la spasticité, ceci dans 24 operations sur I4 malades. Chez un malade, la spasticité unilatérale de l'oblique externe compliquait les symptômes cliniques, et le traitement par une myotomie transversale a donné un bon résultat.

\section{ZUSAMMENFASSUNG}

Schwere spastische Beugekontraktur der Hüfte am Para-und Tetraplegiker ist ein therapeutisches Problem, besonders bei Patienten mit inkompletten Läsionen.

Hohe Myotomie des M. Iliopsoas von einem abdominalen Schrägschnitt aus hat sich in 24 Operationen an I4 Patienten in den letzten 4 Jahren gut bewährt. 3 Wochen nach der Operation konnten I I Patienten wieder aufrecht stehen and 7 Patienten mit Ellbogenkrücken gehen.

Bei einem Patienten mit zusätzlicher spastischer Lumbalskoliose führte Myotomie des rechten M. Obliquus externus abdominis zu weitgehender Korrektur.

\section{REFERENCE}

Fowlen, A. W. (1957). 7th World Congr. Soc. Welfare of Cripples Report, p. 429. 


\section{Discussion}

HARDY, A. G. (England) thought that this was perhaps an opportunity to 'eat his own words'. Some years ago, he had used in a paper to the Royal Society of Medicine the phrase 'destructive procedures', and he thought it was due largely to his friendship and conversations with Dr. Michaelis that he now felt that this was a very wrong expression; it should be 'peripheral corrective procedures', and that was the expression he was now using in all his notes.

The second point was that this was indeed the approach exactly as Dr. Michaelis had described it; they used a supra-inguinal approach, retracting and picking out if they could the genito-femoral as well as the femoral nerve, made a high transverse division of the psoas and iliacus and watched it retract as they pushed the leg down. He could add one little thing; if it did not extend all the way, and one could do this under direct control at the operation, one might sometimes find that one could obtain a little further extension by doing a modified slide from the same incision. They let the tensor fasciae latae go and sometimes even took the rectus femoris as well, sliding them off the crest of the ileum.

Thirdly, with regard to haemostasis, he did not think that the retracted ends of the spastic or formerly spastic iliacus bled very much; this had not been a problem, provided they had taken the precaution of ligating the vessel which often ran down into the tendon; but he had found the nutrient vessels sometimes troublesome and he thought it very important and well worth Io minutes having a look round for haemostasis.

BARDOT, A. (France) said he had performed some such operations with complete satisfaction. He would like to know if anyone had observed abduction following section of the obturator nerve.

MiCHAELIS, L. S. (England) replied that they had. Among about I30 obturator neurectomies they had seen in three patients a tendency towards abduction. Since they had first observed this, they had reduced the position of abduction following operation. One must not keep the legs apart by using more than two pillows; there were certain patients with incomplete lesions, among them the last patient he had demonstrated, who after obturator nerve resection developed spastic contractions of the main abductor, namely the gluteus medius, and in those cases abduction might become quite a nuisance.

GutTMANN, L. (England) would like to stress this point. He had emphasised many years ago that the obturator resection had to be done very selectively. With patients who were suffering only from contractions of the adductor muscles and not contractures, one had to be very careful with bilateral resection of the obturator nerves. In particular, one must be careful in children. Surgeons who had treated spastic children with cerebral palsy found that these abduction contractures might develop, and no doubt an abduction contracture in children was even worse than adduction. What was most striking was the beneficial effect of peripheral operations on the whole reflex synergy. Sometimes, even the elongation of an Achilles tendon might have a marked relaxing effect on the whole spasticity. With regard to flexion contractures of the feet, there was one point which was often forgotten; it was not only the gastrocnemius which was the culprit but also the flexors of the toes, and unless in such cases one also carried out a subcutaneous division of the toe flexors the spasticity could still be very troublesome. Therefore, one could not emphasise too strongly that every case of spasticity had to be considered individually. 